\title{
Optical switching of self-assembly and disassembly of non-convalently connected amphiphiles
}

\section{Supporting Information}

\section{Synthesis}

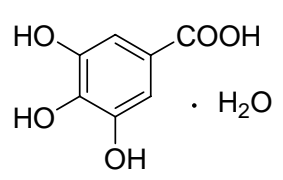

1

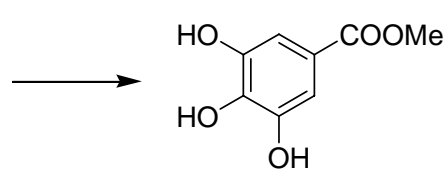

2

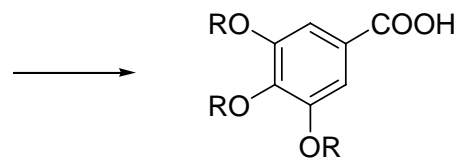

3: $\mathrm{R}=\mathrm{C}_{18} \mathrm{H}_{37}$

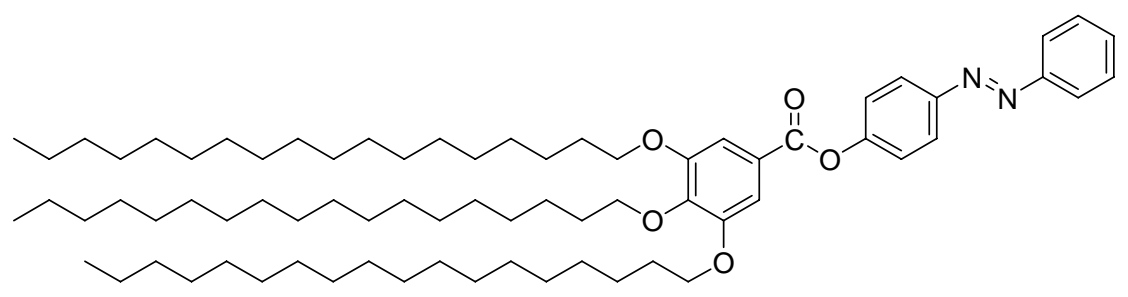

4

(scheme 1) synthesis of hydrophobic azobenzene derivative 4

methyl 3,4,5-trihydroxybenzoate (2): 3,4,5-trihydroxybenzoic acid hydrate $\mathbf{1}$ (3.8g, $20.2 \mathrm{mmol})$, sodium hydrosulfate hydrate $(0.28 \mathrm{~g}, 2.0 \mathrm{mmol})$, and methanol $(30 \mathrm{~mL})$ were heated at reflux for $18 \mathrm{~h}$ before methanol was removed in vacuo. The crude product was recrystallized by water and gave a white power $3.5 \mathrm{~g}$ in $95 \%$ yield. ${ }^{1} \mathrm{HNMR}\left(400 \mathrm{MHz}, \mathrm{CDCl}_{3}, 25^{\circ} \mathrm{C}, \mathrm{TMS}\right): \delta=3.70\left(\mathrm{~s}, 3 \mathrm{H}, \mathrm{COOCH}_{3}\right), 6.92(\mathrm{~s}, 2 \mathrm{H}$, $\mathrm{ArH}), 9.15(\mathrm{~s}, 2 \mathrm{H}, \mathrm{OH})$

${ }^{13} \mathrm{CNMR}\left(400 \mathrm{MHz}, \mathrm{CDCl}_{3}, 25^{\circ} \mathrm{C}, \mathrm{TMS}\right): \quad \delta=166.9,146.1,138.9,119.9,109.0,52.1$ 
3,4,5-tris(octadecyloxy)benzoic acid (3): Compound 5 was prepared as follows [1]. A mixture containing methyl 3,4,5-trihydroxybenzoate $2(0.37 \mathrm{~g}, 2.0 \mathrm{mmol})$, 1-bromooctadecane $(2.0 \mathrm{~g}, 6.0 \mathrm{mmol})$, anhydrous $\mathrm{K}_{2} \mathrm{CO}_{3}(2.76 \mathrm{~g}, 20.0 \mathrm{mmol})$ and $20 \mathrm{ml}$ of dry DMF was purged with $\mathrm{N}_{2}$, and heated at $80{ }^{\circ} \mathrm{C}$ under nitrogen for $24 \mathrm{~h}$. The mixture was then allowed to cool to room temperature. The reaction mixture was poured to $100 \mathrm{ml}$ water and then acidified with $\mathrm{HCOOH}$ till $\mathrm{PH}=4-5$. The reaction mixture was filtered and $1.16 \mathrm{~g}$ gray solid was got. A solution of $0.5 \mathrm{M} \mathrm{KOH}$ in EtOH $20 \mathrm{ml}$ and $1 \mathrm{ml}$ water was added and the mixture was refluxed for $4 \mathrm{~h}$. The solution was acidified with dilute $\mathrm{HCOOH}$ and precipitated into water. DCM (30ml) was added for extraction and the organic layer was then separated. The water phase was extracted by DCM (20ml) three times, dried over $\mathrm{MgSO}_{4}$, filtered and the solvent was evaporated. The product was purified by column chromatography (silica gel, DCM and EA as eluent) giving a white powder $1.04 \mathrm{~g}$ in $56 \%$ yield.

${ }^{1} \mathrm{HNMR}\left(400 \mathrm{MHz}, \mathrm{CDCl}_{3}, 25^{\circ} \mathrm{C}, \mathrm{TMS}\right): \delta=0.87\left(\mathrm{t}, 9 \mathrm{H}, \mathrm{CH}_{3} \mathrm{CH}_{2^{-}}\right)$, 1.25,1.45(overlapped peaks, $\left.90 \mathrm{H}, \mathrm{CH}_{2} \mathrm{~s}\right), 1.77\left(\mathrm{~m}, 6 \mathrm{H}, \mathrm{C}_{2} \mathrm{CH}_{2} \mathrm{O}\right), 4.01\left(\mathrm{t}, 6 \mathrm{H}, \mathrm{C}_{2} \mathrm{O}\right)$, 7.30(s, 2H, ArH).

(E)-4-(phenyldiazenyl)phenyl 3,4,5-tris(octadecyloxy)benzoate (4): A solution of $0.1 \mathrm{~g}(0.11 \mathrm{mmol})$ of 3,4,5-tris(octadecyloxy)benzoic acid $5,0.022 \mathrm{~g},(0.11 \mathrm{mmol})$ of 4-(phenyldiazenyl)phenol, $0.022 \mathrm{~g}(0.11 \mathrm{mmol})$ of DCC and $0.01 \mathrm{~g}(0.09 \mathrm{mmol})$ of DMAP in $20 \mathrm{ml}$ DCM was stirred for $48 \mathrm{~h}$ at reflux. The resulting precipitate was filtered and the DCM was evaporated on a rotovapor. The product was purified by column chromatography (silica gel, PE and EA as eluent) gave orange solid to yield $72 \%$.

${ }^{1} \mathrm{HNMR}\left(400 \mathrm{MHz}, \mathrm{CDCl}_{3}, 25^{\circ} \mathrm{C}, \mathrm{TMS}\right): \delta=0.87\left(\mathrm{t}, 9 \mathrm{H}, \mathrm{C}_{3} \mathrm{CH}_{2^{-}}\right)$, 1.25,1.47(overlapped peaks, $90 \mathrm{H}, \mathrm{CH}_{2} \mathrm{~s}$ ), $1.82\left(\mathrm{~m}, 6 \mathrm{H}, \mathrm{C}_{2} \mathrm{CH}_{2} \mathrm{O}\right), 4.05\left(\mathrm{t}, 6 \mathrm{H}, \mathrm{C}_{2} \mathrm{O}\right)$, 7.36(d, 2H, azobenzene ortho from-OOC-Ph), 7.42(s, 2H, -OOC-Ph프), 7.51(m, 3H, 
azobenzene meta $2 \mathrm{H}$ and para $1 \mathrm{H}$ from $-\mathrm{N}=\mathrm{N}-\mathrm{Ph}-\mathrm{OOC}), 7.91(\mathrm{~d}, 2 \mathrm{H}$, azobenzene ortho from $-\mathrm{N}=\mathrm{N}-\mathrm{Ph}-\mathrm{OOC}), 8.00(\mathrm{~d}, 2 \mathrm{H}$, azobenzene meta from $-\mathrm{OOC}-\mathrm{Ph})$

${ }^{13} \mathrm{CNMR}\left(400 \mathrm{MHz}, \mathrm{CDCl}_{3}, 25^{\circ} \mathrm{C}, \mathrm{TMS}\right): \quad \delta=164.9,153.2,153.1,152.7,150.4$, $143.2,131.1,129.2,124.2,123.7,123.0,122.6,108.7,73.7,69.4,32.0,30.4,29.8$, $29.5,26.2,22.8,14.2$

IR (KBr plate): $2920 \mathrm{~cm}^{-1}, 2851 \mathrm{~cm}^{-1}$ ( $\mathrm{v}-\mathrm{CH}_{2}$ acyclic), $1733 \mathrm{~cm}^{-1}$ ( $\left.\mathrm{v}-\mathrm{C}=\mathrm{O}\right), 1431$ $\mathrm{cm}^{-1}(\mathrm{v}-\mathrm{N}=\mathrm{N}$, trans $)$

MALDI-TOF MS: m/z calcd for $\mathrm{C}_{73} \mathrm{H}_{122} \mathrm{~N}_{2} \mathrm{O}_{5}[\mathrm{M}+\mathrm{Na}]^{+}:$1129.9; found: 1129.4,1131.5, 1132.5, 1133.5 multipeaks.

\section{Measurements}

A commercial laser light scattering (LLS) spectrometer (Malvern Autosizer 4700) equipped with a multi- $\tau$ digital time correlation (Malvern PCS7132) and a solid-state laser (ILT 5500QSL, $100 \mathrm{~mW}$ output at $\lambda_{0}=532 \mathrm{~nm}$ ) and a CONTIN program are used. All the DLS measurements were performed at a fixed scattering angle $(\theta)$ of $90^{\circ}$ at $25.0 \pm 0.1{ }^{\circ} \mathrm{C}$. TEM observations were performed on a Philips CM 120 microscope at an accelerating voltage of $80 \mathrm{KV}$. The specimens were prepared by depositing $10 \mu \mathrm{L}$ of aggregates solution which was diluted 10 times by water on carbon-coated grids. ${ }^{1}$ HNMR (400MHz) spectra were performed on a JEOL JNM-ECA-400 with TMS as the internal standard. Matrix-assisted laser desorption ionization time of-flight (MALDI-TOF) mass spectra were recorded by using an Applied Biosystems Voyager-DE STR, using trans 3-indoleacrylic acid as the matrix, observing reflector-positive ions. UV irradiation was carried out with a CHF-XM35-500W high-pressure mercury lamp coupled with UV filters $(365 \mathrm{~nm}) \mathrm{E}=2000 \mathrm{mw} / \mathrm{cm}^{2}$. Irradiation by visible light was performed using filters $(434 \mathrm{~nm}) . \mathrm{E}=200 \mathrm{mw} / \mathrm{cm}^{2}$. UV/Vis spectra were recorded on a Perkin-Elmer Lamda 35 UV/Vis spectrophotometer. 


\section{UV and visible light irradiation}

The photoisomerization of azobenzene group of 3C18Azo in THF solution $0.3 \mathrm{mg} / \mathrm{ml}$ by UV (Figure S1-a) and visible light (Figure S1-b) is monitored by UV-vis spectra:

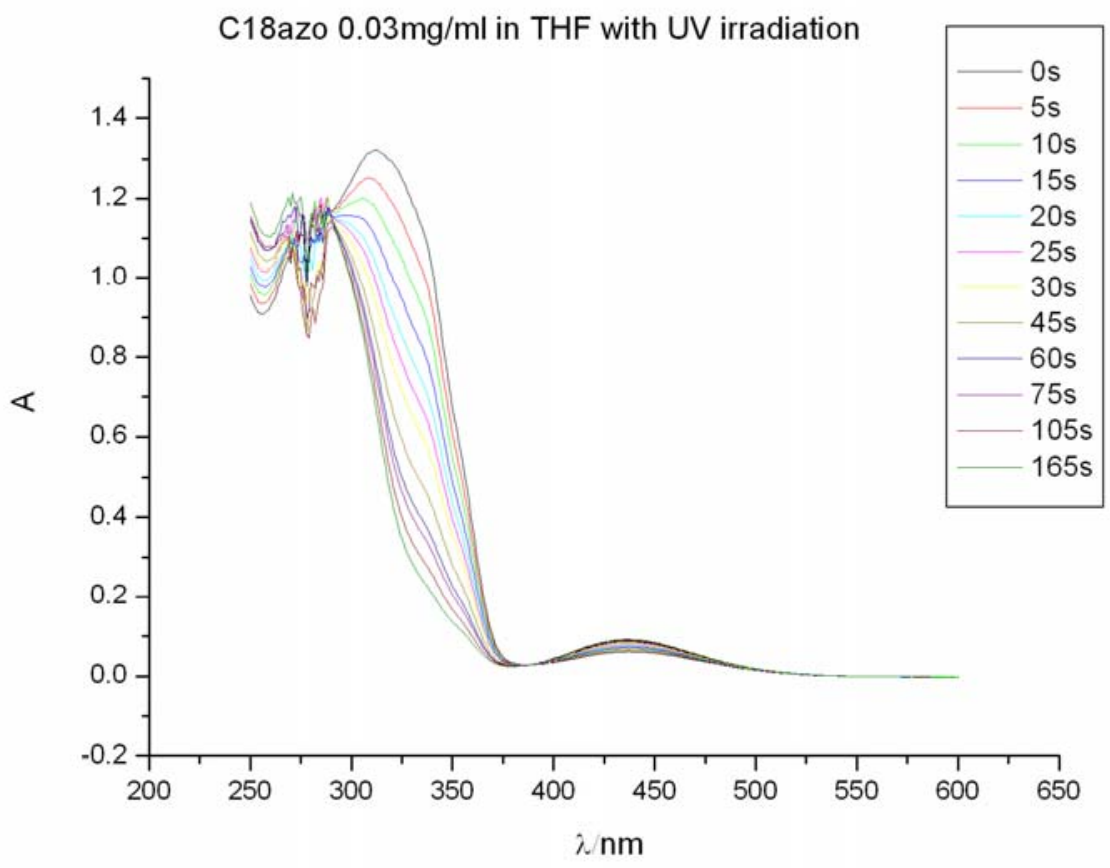

Figure S1-a 
UV irradiated $C_{18 a z 0} 0.03 \mathrm{mg} / \mathrm{ml}$ in THF with $\mathrm{Vis}(\lambda=434 \mathrm{~nm})$ irradiation

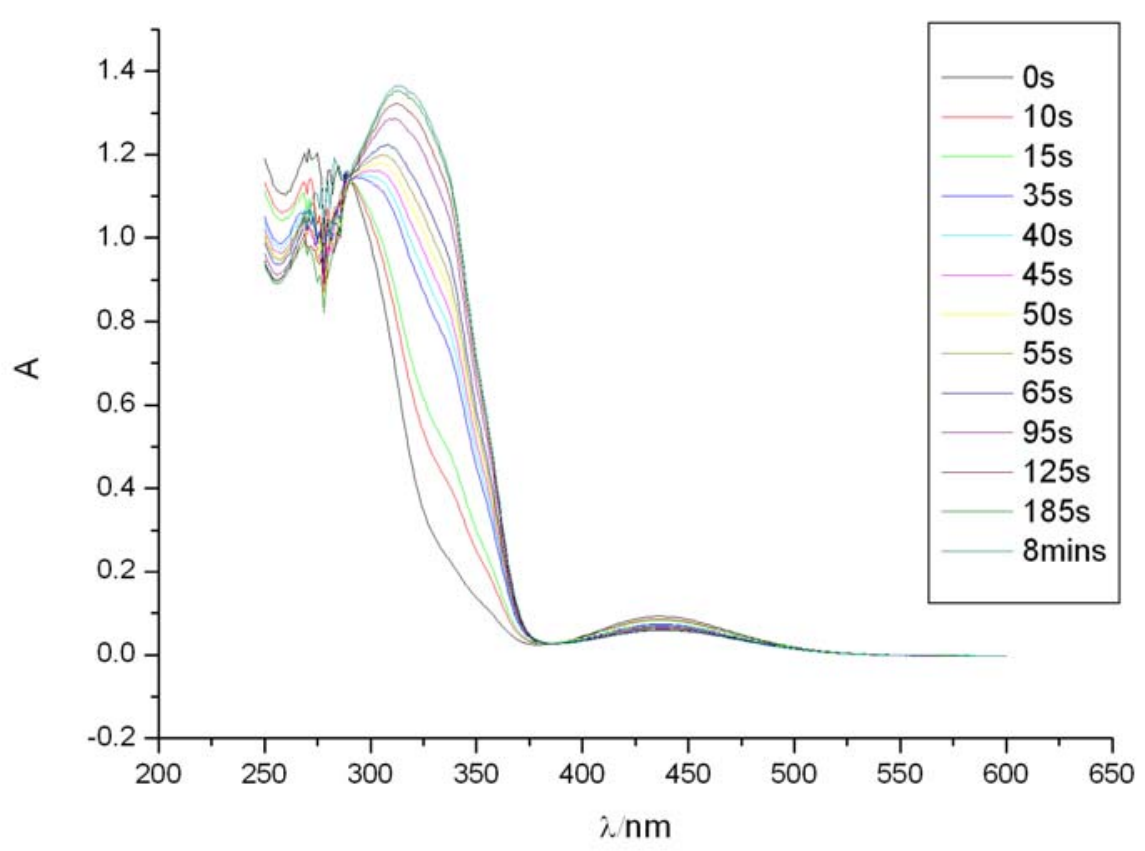

Figure S1-b

UV/Vis spectroscopy of Sample B

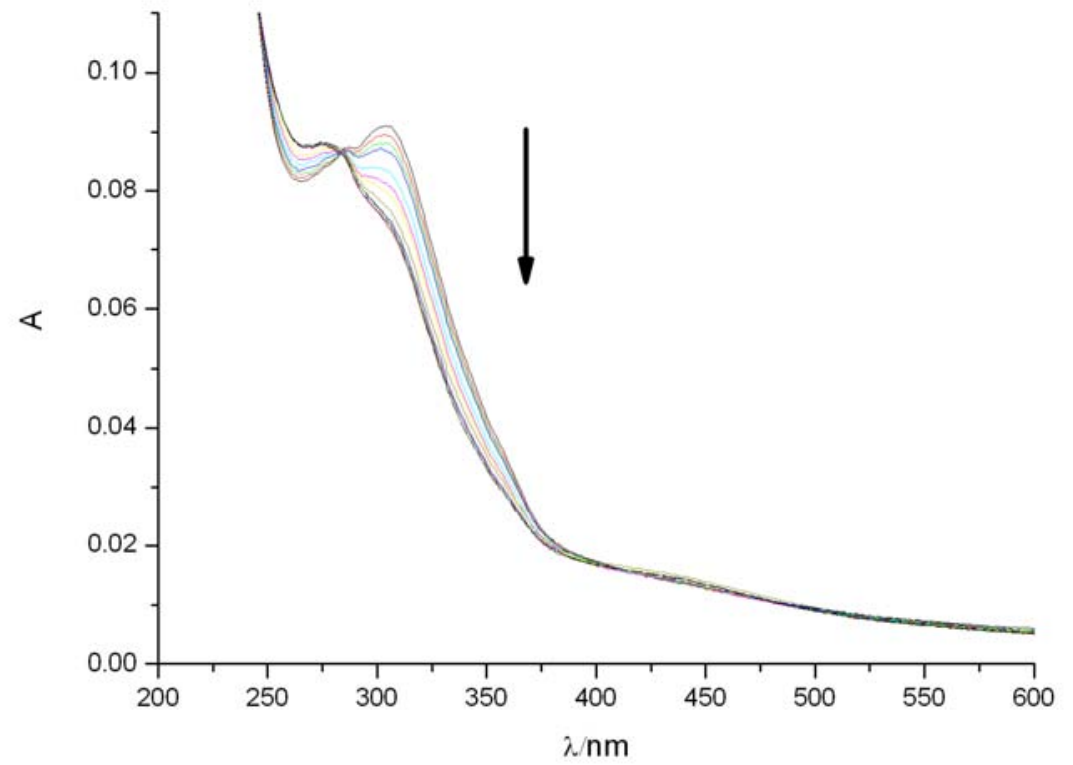


Figure S2-a Sample B with UV irradiation $(\lambda=365 \mathrm{~nm})$, from the top down UV irradiation for $0,5,10,15,35,55,75,120,180,240,540$ and 1140 s.

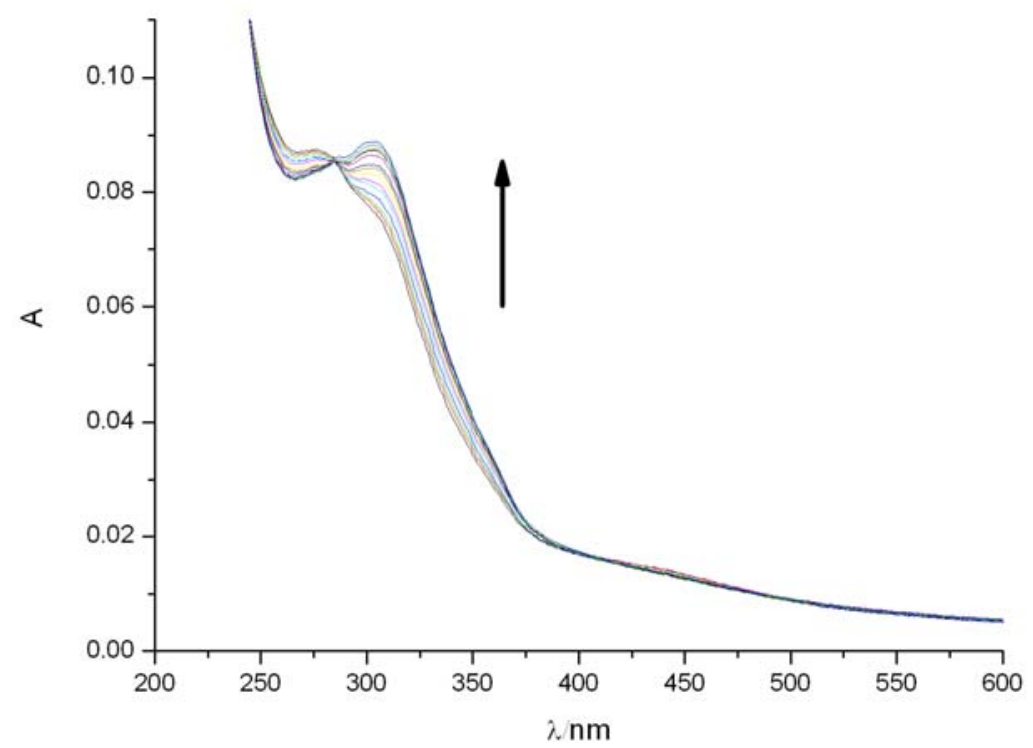

Figure S2-b Sample B with Visible light irradiation $(\lambda=434 \mathrm{~nm})$, from the bottom up vis-irradiation for $5,10,15,20,25,35,45,65,85,105,180,240,300,600$ and 1200 s.

Table S1: $\mathrm{D}_{\mathrm{h}}$ and PDI of Sample $\mathbf{A}$ and those prepared at the same conditions showing the reproducibility of results (A1-A5).

\begin{tabular}{ccccc}
\hline Entry & $\mathrm{D}_{\mathrm{h}}[\mathrm{nm}]$ & $\mathrm{PDI}\left[\mu_{2} /<\Gamma>^{2}\right]$ & $\begin{array}{c}\text { Concentration } \\
\text { of } 4 \text { in THF/ } \\
{[\mathrm{mmol} / \mathrm{ml}]}\end{array}$ & $\alpha-\mathrm{CD}$ in \\
water $/[\mathrm{mmol} / \mathrm{ml}]$
\end{tabular}




$\begin{array}{lllll}\text { A3 } & 246 & 0.25 & 0.09 & 1.03 \\ \text { A4 } & 267 & 0.24 & 0.09 & 1.03 \\ \text { A5 } & 256 & 0.26 & 0.09 & 1.03\end{array}$

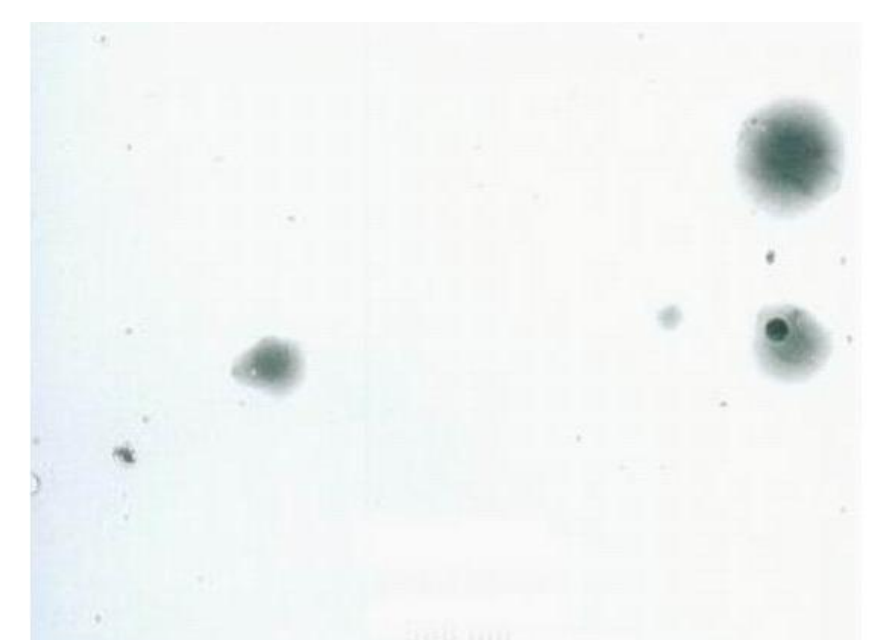

$500 \mathrm{~nm}$

Figure S3: TEM image of the aggregates formed by injecting $0.1 \mathrm{ml}$ THF solution of 3C18Azo $(1 \mathrm{mg} / \mathrm{ml})$ into $2 \mathrm{ml}$ water.

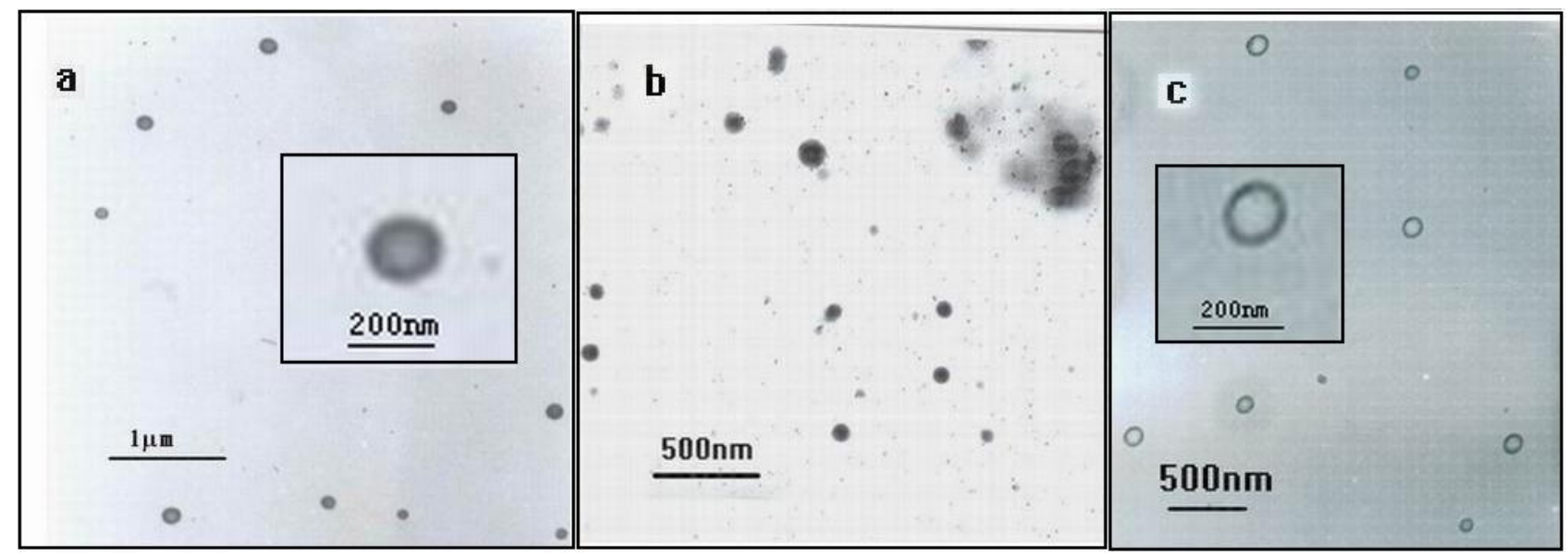


Figure S4: TEM micrographs of sample B (a): self-assembled vesicles. (b): UV irradiated sample a forming irregular aggregates. (c): Visible light irradiated sample b forming vesicles.

Reference

(1) V. Percec and J.Heck, Polym. Bull,. 1991, 25, 431. 